\title{
The addition of peak expiratory flow monitoring to symptom-based self management did not enhance outcome in children with asthma
}

Wensley D, Silverman M. Peak flow monitoring for guided self-management in childhood asthma: a randomized controlled trial. Am J Respir Crit Care Med 2004;170:606-12.

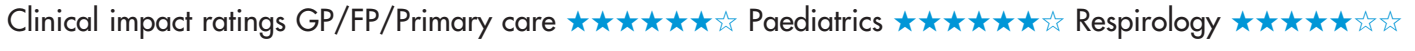

In children with asthma, does the addition of routine peak expiratory flow (PEF) monitoring to symptom-based self management improve outcome over symptom-based self management alone?

METHODS

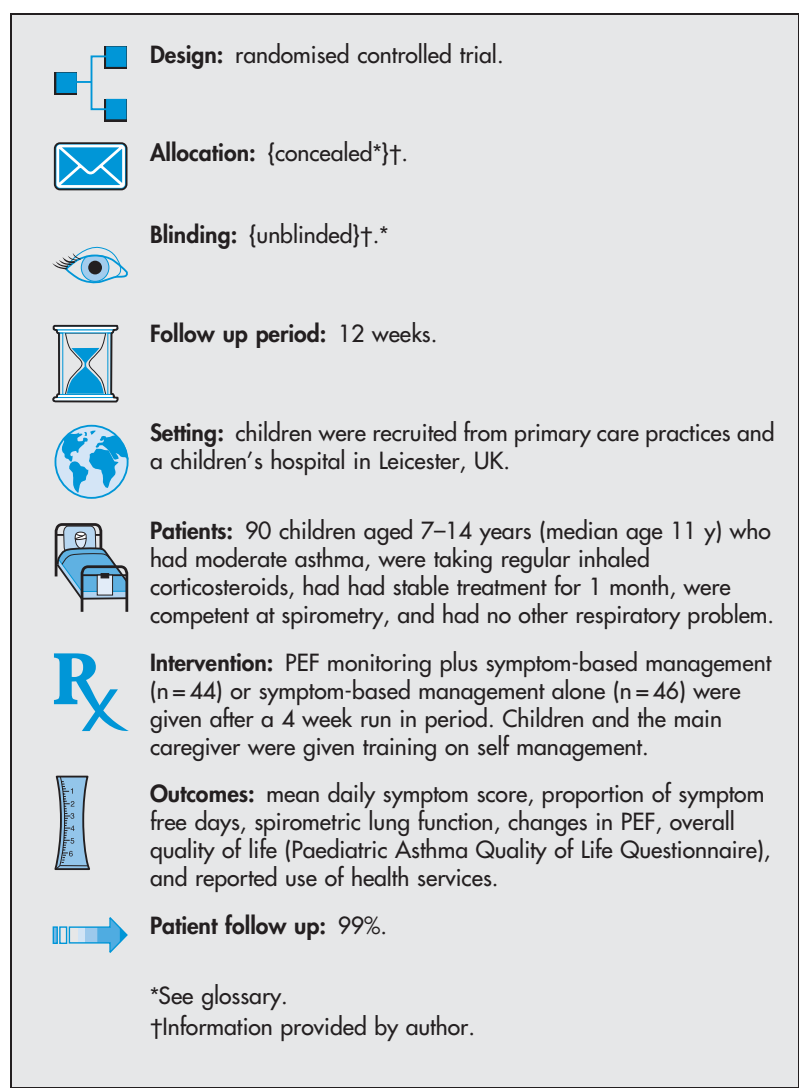

\section{MAIN RESULTS}

No differences were seen between the 2 groups in proportion of symptom free days (table), mean daily symptom score, spirometric lung function, changes in PEF, overall quality of life, or reported use of health services.

For correspondence: DrM Silverman, Leicester Royal Infirmay, Leicester, UK ms70@le.ac.uk

Sources of funding: United Kingdom Asthma Campaign and Glaxo SmithKline.

\section{CONCLUSION}

In children with asthma, the addition of routine peak expiratory flow monitoring to symptom-based self management did not enhance outcome over symptom-based self management alone.

\section{Commentary}

D atient education on self management of their asthma is a cornerstone of proper medical care. ${ }^{1}$ As part of this process, an individualised action plan should be developed in collaboration with the child and parents. The study by Wensley and Silverman tested whether an action plan with self management decisions based upon PEF monitoring was more effective than one based upon symptoms for the care of children with asthma.

This methodologically strong study showing no benefit to PEF monitoring differed from a previous study, ${ }^{2}$ which showed advantages of PEF monitoring in 2 potentially important ways. This study tested PEF use among 7-14 year olds with stable asthma, whereas the previous study included adolescents and adults who were seen after a visit to the emergency department for an asthma exacerbation. It is quite certain that successful use of PEF monitoring is age dependent, with children generally unable to do it successfully before 7 years of age. In addition, a patient's or family's receptiveness to learn and use PEF monitoring might vary by their perceived risk of the disease, which presumably would be greater among patients recently seen for an exacerbation than those with stable disease.

It now seems clear that PEF monitoring is not advantageous for most adults and children with asthma. ${ }^{3}$ Patient education for children must remain developmentally appropriate for the growing child and move from being parent centred to being directed to the patient. During this continuing and collaborative process, it should become apparent whether the patient is being self managed successfully with a symptom-based action plan or might benefit from a trial of PEF monitoring. The addition of PEF monitoring to the self management plan remains a relatively simple and economical alternative for children who are able to perform PEF in the office, yet struggle to perceive onset of asthma exacerbations by symptoms alone.

Thomas M Ball, MD, MPH University of Arizona Tucson, Arizona, USA

1 Gibson PG, Powell H, Coughlan J, et al. Self-management education and regular practitioner review for adults with asthma. Cochrane Database Syst Rev 2003;(1):CD001117.

2 Cowie RL, Revitt SG, Underwood MF, et al. The effect of a peak flow-based action plan in the prevention of exacerbations of asthma. Chest 1997:112:1534-8.

3 Powell H, Gibson PG. Options for self-management education for adults with asthma. Cochrane Database Syst Rev 2003;(1):CD004107.

Peak expiratory flow monitoring plus symptom-based self management (intervention) $v$ symptom-based self management alone (control) in children with asthma*

\begin{tabular}{lllll}
\hline Outcome at $\mathbf{1 2}$ weeks & Intervention & Control & RBI (95\% CI) & NNT \\
\hline Proportion of symptom free days & $70 \%$ & $60 \%$ & $18 \%(-14$ to 63) & Not significant \\
\hline
\end{tabular}

*Abbreviations defined in glossary; RBI, NNT, and Cl calculated from data in article. 